[When citing this chapter, refer to Behaviour 152 (2015) 359-374]

\title{
Can fruiting plants control animal behaviour and seed dispersal distance?
}

\author{
David Beaune $^{\mathrm{a}, \mathrm{b}, *}$, François Bretagnolle $^{\mathrm{b}, \mathrm{c}}$, Loïc Bollache $^{\mathrm{d}, \mathrm{e}}$, \\ Gottfried Hohmann ${ }^{\text {a }}$ and Barbara Fruth ${ }^{\mathrm{a}}$ \\ ${ }^{a}$ Max Planck Institute for Evolutionary Anthropology, Department of Primatology, \\ Deutscher Platz 6, 04103 Leipzig, Germany \\ ${ }^{\mathrm{b}}$ Laboratoire Biogéosciences, UMR CNRS 6282, Université de Bourgogne, \\ 6 boulevard Gabriel, 21000 Dijon, France \\ c UMR 5175 CEFE-CNRS, 1919 Route de Mende, 34293 Montpellier 5, France \\ d INRA, UMR 1347 Agroécologie, BP 86510, 21000 Dijon, France \\ ${ }^{\mathrm{e}}$ Université de Bourgogne, 6 boulevard Gabriel, 21000 Dijon, France \\ *Corresponding author's e-mail address: david.beaune@gmail.com
}

Accepted 31 March 2014; published online 7 May 2014

\begin{abstract}
In an Afrotropical forest, we tested the hypothesis that fleshy-fruit plants with interspecific differences in fruit quality and quantity affect ranging behaviour of their seed dispersal vector. If fruiting plants could affect their dispersal vector, the plants also affect their seed dispersal distance and eventually their plant population biology. From 2007 to 2011, we measured seed transport by georeference daily bonobo group movements via GPS. Seed dispersal distance was estimated with mechanistic model, using 1200 georeferenced dispersal events and the average seed transit time through bonobo $(24.00 \mathrm{~h})$. We compared dissemination for eight plant species that deal with this trade-off: attracting dispersers by means of fruit quality/quantity versus retaining them in the patch because of the same quality/quantity value that attracted them. Because fruit traits of these eight species were different, we expected a difference in seed dispersal distance. Surprisingly, seed dispersal distances induced by bonobos were not affected by fruit traits. Although fruit nutrient contents, abundance and average patch feeding duration differed between plant species, patch feeding time was not related to subsequent dispersal distances. The apes' dispersal distance survey gave an average dispersal distance estimated of $1332 \pm 24 \mathrm{~m}$ from the parent plant $(97.9 \%>100 \mathrm{~m})$. To conclude, feeding time invested in the patch, fruit quality and abundance had no apparent effect on bonobo seed dispersal distance. The possible effects in plant population biology are discussed.
\end{abstract}

\section{Keywords}

Africa, bonobo, Congo Basin, dispersal distance, foraging behaviour, forest structure, mutualism, optimal foraging, Pan paniscus, seed dispersal, zoochory. 


\section{Introduction}

The spatial pattern of seed deposition such as dispersal distance is an aspect of dispersal ecology that may have major consequences on several aspects of plant population dynamics as well as on plant community structure and dynamics (Jordano, 1995; Levin et al., 2003; Howe \& Miriti, 2004; Schupp et al., 2010). However data that quantify real dispersal patterns are scarce, particularly concerning forest species dispersed through endozoochory (Clark et al., 2005; Russo et al., 2006; McConkey \& Chivers, 2007; Cousens et al., 2010). For zoochoric plants, the spatial distribution of seed deposition (i.e., seed shadows, Willson, 1993) results from the movement and behaviour of animals that feed on the fruit and transport the seeds (Westcott et al., 2005). Frugivores can shape spatial configuration of their food species, in numerous interactive ways such as by foraging decisions and by migration behaviour (Jordano et al., 2007; Spiegel \& Nathan, 2007; Carlo \& Morales, 2008). By that they will influence the shape of the probability distribution of the seed dispersal distance that depends on the disperser distance from the source and its seed retention time (Westcott et al., 2005; Russo et al., 2006; Cousens et al., 2010). The gut transit time of the seed is another parameter that could potentially affect the probability distribution of dispersal and very few studies show that this parameter can be affected by seed size and chemical components of the fruit that can increase or decrease seed transport time (Levey \& Grajal, 1991; Gardener et al., 1993; Westcott et al., 2005; Tsuji et al., 2010a). The seed dispersal distances for animals with short gut passage time, such as birds is related to the time spent in fruiting trees (Lenz et al., 2010). The quantity and the quality of fruits produced by an individual plant as well as the level of aggregation of fruiting plants in a landscape can also affect the probability distribution of seed dispersal (Carlo \& Morales, 2008). If the food patch can sustain the dispersers for a time superior to the transit time, or if the dispersers frequently return to the patch, and remain in its vicinity, the amount of seeds transported can be high while dispersal distance is low. For example, orang-utans can select large fruiting trees that they repeatedly visit staying around between feeding bouts (Leighton, 1993). In other words an optimal foraging theory would predict that food quality/quantity would negatively affect the animals' foraging effort (daily travel distance). Large and medium-sized frugivores, such as elephants or apes disperse numerous plant species (Campos-Arceiz \& Blake, 2011; Forget et al., 2011). In 
the lowland tropical rainforest of Congo, $85 \%$ of the plant species $(95 \%$ of the tree species) produce fleshy fruits and rely on animals for primary seed dispersal (Beaune et al., 2013b). The bonobos (Pan paniscus Schwarz) are efficient seed dispersers that transport viable seeds of several fruiting species by endozoochory (Idani, 1986; Tsuji et al., 2010b; Beaune et al., 2013c). Bonobos have a long gut passage time ( $24 \mathrm{~h} 00 \mathrm{~min}$, Beaune et al., 2013a) and are wide-ranging animal foraging on many fruiting plants during a day although occasionally they stay around a big fruiting tree and/or frequently come back to this patch (Beaune et al., 2013a, c). Plant populations are affected by the dispersal distance, which depends on dispersal vectors, but can the plant affect the behaviour of their mutualistic partners? Here we test the hypothesis that plant species with different fruit production strategies can affect the behaviour of their disperser and, consequently, their seed dispersal distance. (a) Fruiting trees that produce large quantities and/or highly nutritive fruit can attract and maintain the disperser in place, resulting in a low seed dispersal distance. Conversely, (b) trees with limited fruit production could achieve a high dispersal distance although being less attractive.

For this, we first analyse whether or not bonobos exhibit variation in the time they spend in fruiting trees. We compare the difference in quality and quantity of the fruiting species with analysis of the fruit nutrient composition, traits and the average feeding duration of the bonobo parties (sub-groups) in the fruiting species. Secondly we develop a mechanistic estimation of seed dispersal for more than 50 zoochoric plant species incorporating seed transit time and the empirical movement behaviour of the bonobos as common dispersers for all these species. Many tropical plants have evolved fleshy fruit that are attractive to only a limited subset of frugivores (Fleming, 1979). Afrotropical forest frugivores use different canopy strata with low feeding overlap (Fleming, 1979; Clark et al., 2001; Poulsen et al., 2002). Bonobos can be considered as main seed dispersers for the fruiting species selected here, although alternative dispersers such as birds, rodents and other primates cannot be excluded (Beaune, 2012; Beaune et al., 2013a).

We compared dispersal distances for several tree species with different species traits and fruit production strategies (see Table 1). Those dispersal distances can be used to test whether fruiting plants affect their frugivore ranging behaviour and thus control their zoochoric partners for seed dispersal distance and eventually affecting their population biology. 


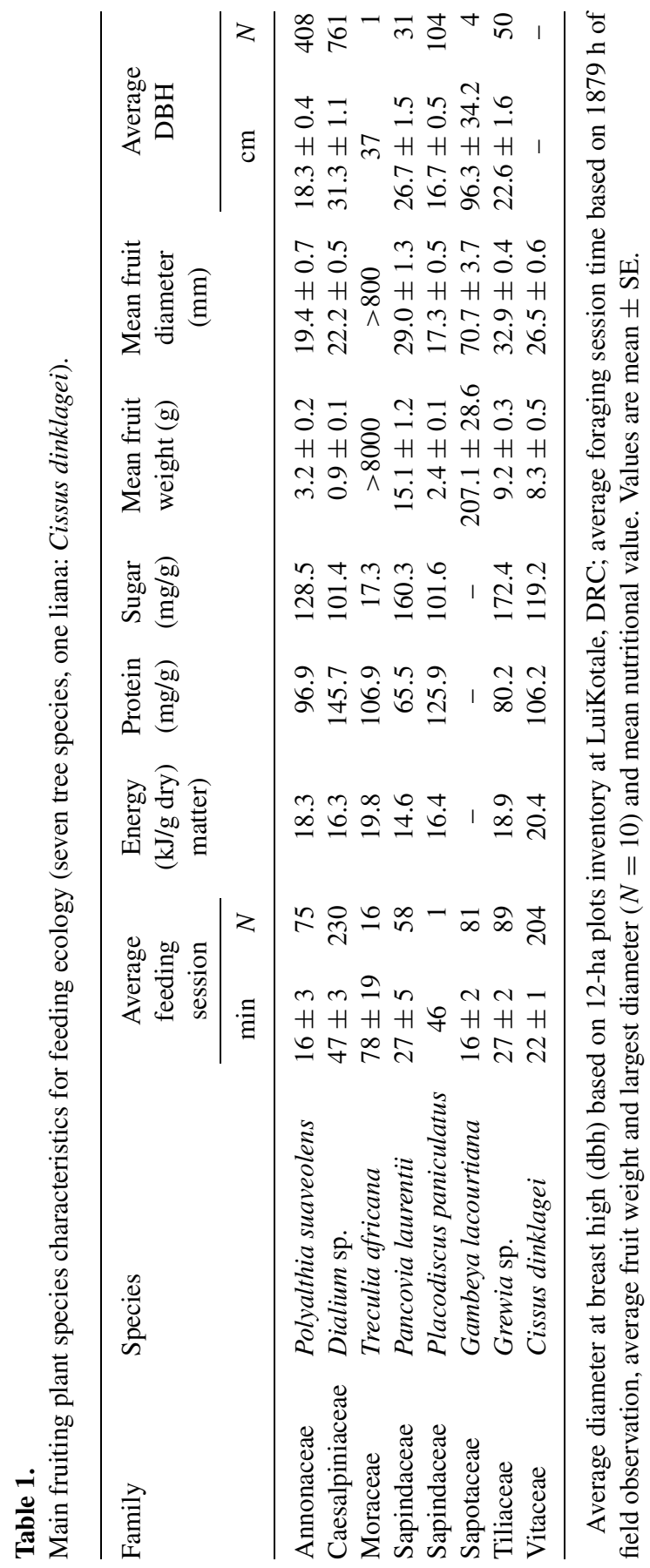




\section{Methods}

\subsection{Study species and site}

The bonobo is restricted to the tropical rain forest of the Democratic Republic of Congo (DRC) on the southern bank of the Congo River. The bonobo is mainly frugivores, feeding on and disseminating hundreds of plant species (Kano \& Mulavwa, 1984; Tsuji et al., 2010b). Seeds of around 40\% of the tree species in the forest are dispersed by bonobos (Beaune et al., 2013c). Bonobos live in polyandrogynous communities with fission of subunit groups (parties) during the day while foraging, and fusion in the nesting place at night (Fruth \& Hohmann, 1993). In the Congo Basin, at the southwest fringe of the Salonga National Park, there is a habituated group of free-ranging bonobos, tracked by research teams at the LuiKotale field site (LK) (Hohmann \& Fruth, 2003). The bonobo community includes 25-35 individuals identifiable by individual physical traits (genital, face, pilosity, color). The long-term project of LuiKotale with a habituated bonobo community which can be daily observed, identified, followed and georefenced by researchers, allowing us to build a mechanistic model of seed dispersal distance (Figures 1 and 2).

\subsection{Ethics statement}

The studied apes are free ranging bonobos observed without invasive methods, constraint, contact or any interaction with the researchers. Animal welfare had greater priority than scientific interests. The methods used to collect data in the field are in compliance with the requirements and guidelines of the Institut Congolais pour la Conservation de la Nature, and adhere to the legal requirements of the host country, the DRC.

\subsection{Dispersal analysis}

The probability distribution of seeds is based on empirical bonobo movements, georeferenced from 8th of July 2007 to the 21st of September 2011. With bonobo movements (i.e., group movements) recorded after observed feeding sessions in feeding trees georeferenced (Figure 1) and mean transit time of seeds known (see below), a mechanistic model of seed dispersal distance can be calculated (Westcott et al., 2005; Tsuji et al., 2010b; Côrtes \& Uriarte, 2012). For example, if a bonobo group is observed feeding in an Gambeya lacourtiana identified and georeferenced at 8.05 a.m. and continuously followed for at least $24 \mathrm{~h}$ (and then including at least one or several 


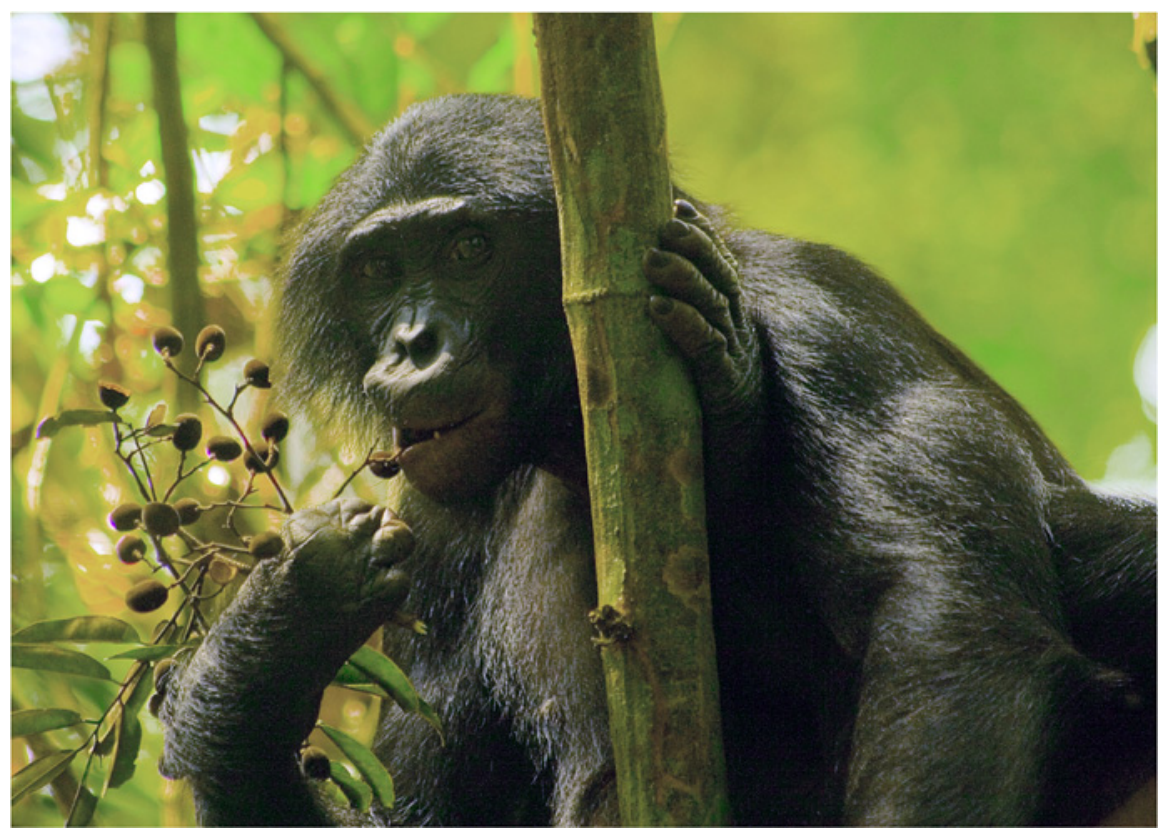

Figure 1. An habituated and identified bonobo of the party (here Emil) is swallowing the fruits and seeds of Dialium sp. at LuiKotale, DRC. The party is geolocalised at this point and continuously during $24 \mathrm{~h}$ (with GPS track log, including at least Emil) for an estimation of this seed dispersal event. Photo by LKBP/David Beaune. This figure is published in colour in the online edition of this journal, which can be accessed via http://booksandjournals. brillonline.com/content/journals/1568539x.

individuals followed since the record), the seed dispersal distance from the parent tree is calculated after the georeferenced position of the bonobo party at $8.05+24.00 \mathrm{~h}$ (mean transit time, see Figure 2). Whenever possible, a bonobo party was followed daily from nest to nest (approx. 05:30 to 17:30). Daily travel routes of parties were tracked with a GPS (Garmin ${ }^{\circledR}$ 60CSX) using 1 point position $/ 5 \mathrm{~min}$ for georeferencing. Bonobo transit time was calculated from direct observations $(24.00 \mathrm{~h} \pm 9 \mathrm{~min} \mathrm{SE})$ and was not affected by the seed size or by bonobo gender (Beaune et al., 2013a). Bonobo feeding trees were georefenced when identified during group feeding sessions. The most abundant fruiting species eaten by bonobo were selected and seed dispersal calculations compared to test our hypotheses. The nonparametric dispersal distance with species effects (i.e., fruit trait) were tested with Kruskal-Wallis one-way analysis of variance. 


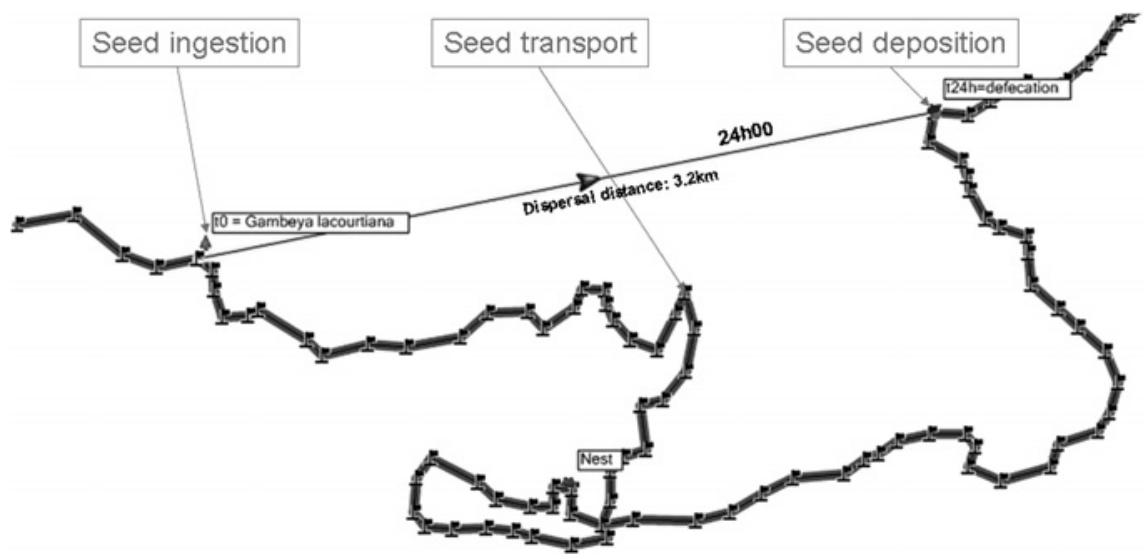

Figure 2. Illustration of the mechanistic seed dispersal model with an example of seed transport (Gambeya lacourtiana). Identified bonobo feeding trees were georeferenced during group observations (2007-2011, LuiKotale, DRC) and bonobo group movement daily recorded (dark track $\log$ ). Theoretical seed deposition site were determined by actual bonobo group position (dark track log) after $24.00 \mathrm{~h}$, corresponding to the average transit time for seed through bonobo.

\subsection{Variation in feeding time session}

Feeding durations were estimated by direct observation of the LK bonobo community. From September 2009 to June 2011 behavioural data of bonobos were recorded for 315 days across 22 months of observations. Bonobos are a fission-fusion society that is depending on season and time of day the community splits up into smaller foraging subgroups called parties (White, 1988). Males and female bonobos forage together, and the offspring follow their mothers, an individual effect on seed dispersal distance is by consequent not considered. As parties are largely cohesive and bonobos feed in group, synchronising their feeding sessions, we considered group feeding activity to be that of the majority of the visible animals during a continuous behavioural records (a party feeding boots was recorded when $>50 \%$ of the bonobos from a party under observation entered a feeding tree and started feeding until $>50 \%$ of the animal terminated feeding and the party moved on or changed its activity, i.e., group scan; Beaune et al., 2013a). As our estimates of dispersal distances are also at the party level, using this party-level feeding metric is appropriate for the purposes of this study. A total of $573 \mathrm{~h}$ of feeding session with fruiting species was analysed. Among these group feeding sessions, the potential correlation of 278 dispersal events 
linked with feeding duration from 22 different fruiting species was analysed with Spearman correlation.

\subsection{Interspecific fruit differences}

Fleshy-fruited plant species are different in fruit production and quality (Hohmann et al., 2006, 2010). The aim of this study was to test whether fruit production and quality affect the probability of seed dispersal distance. We contrasted medium-sized tree species with relatively low fruit production (i.e., Polyalthia (= Greenwayodendron) suaveolens, Placodiscus paniculatus) and large-sized fruiting trees which support and maintain dispersers for longer periods (i.e., Dialium corbisieri and Gambeya lacourtiana). To estimate the mean fruit abundance of each selected species we have calculated the diameter at breast height (dbh) (Chapman et al., 1992). The mean dbh was calculated for the main species, based on a 12-ha plot inventory (Beaune et al., 2013d). One liana, Cissus dinklagei, was added to the test and compared with the seven tree species, for a total of eight species analysed. Fruits from LK forest were collected for nutrient analyses (Hohmann et al., 2006; Hohmann et al., 2010). Average fruit mass and diameter were measured on at least ten mature fruits.

\section{Results}

Table 1 reports differences in nutritional values, fruit size, weight and dbh for adult trees, and mean feeding duration in fruiting species. Bonobo parties spent an average of $30 \pm 2 \mathrm{~min}\left(\mathrm{CI}_{95 \%}=27-34 \mathrm{~min}\right.$; range $\left.=1-168 \mathrm{~min}\right)$ feeding in fruiting plants $(N=22$ species using bonobo seed dispersal service among 91 identified in another study, Beaune et al., 2013c). Although feeding times differed among species (see Table 1; three species tested: $N=50$ Cissus dinklagei, 122 Dialium sp., 27 Grewia sp.; $H=15.1015$, df $=2, p=0.0005257$ ), bonobo party feeding time did not correlate with the 24-h dispersal distance ( $r=-0.07, p=0.2422$; see Figure 3).

We calculated seed transport for 51 different endozoochoric plant species ( $N=1-362$ events). The average dispersal distance \pm SD from the parent plant is $1332 \pm 24 \mathrm{~m}$, median $=1198 ; \mathrm{CI}_{95 \%}=1282-1380 \mathrm{~m}$; range $=$ 1-4492 $\mathrm{m}$. The resulting dispersal distance kernel is a probability density function (Figure 4), characterized by a unimodal leptokurtic distribution, with a fat-tailed dispersal kernel (i.e., with exceptional seed transports at 

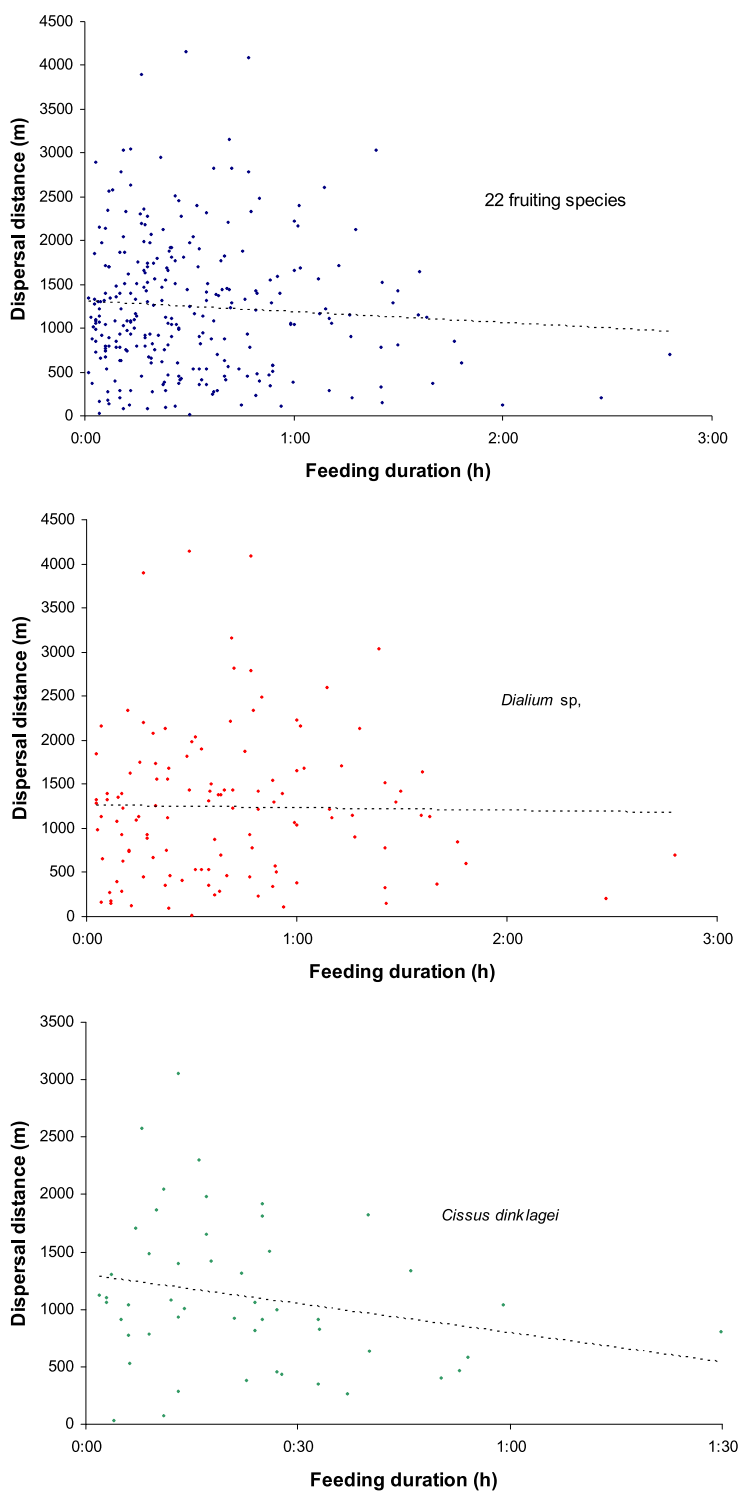

Figure 3. There is no correlation between feeding time spent by the bonobo group on the fruiting plant and the dispersal distance induced by the group after $24 \mathrm{~h}$. For 22 fruiting species analysed as whole $(N=278, r=-0.07, p=0.2422)$ or other species as Dialium sp. (122, $r=-0.01, p=0.8572)$ or Cissus dinklagei (50, $r=-0.22, p=0.1178)$ at LuiKotale, DRC. This figure is published in colour in the online edition of this journal, which can be accessed via http://booksandjournals.brillonline.com/content/journals/1568539x. 


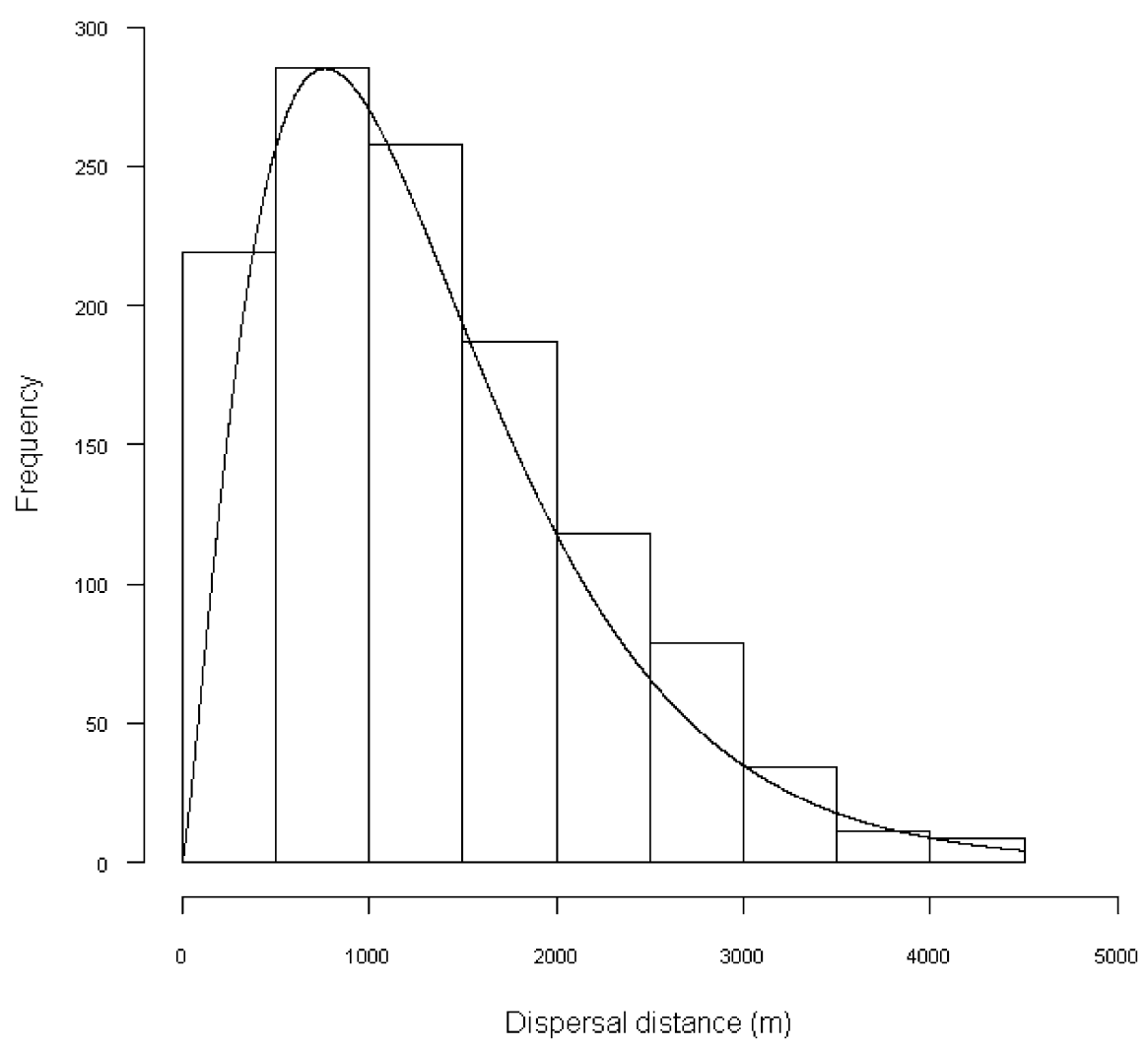

Figure 4. Seed dispersal distribution induced by bonobo based on group movement behaviour $(N=1200$ dispersal events with all plant species at LuiKotale, DRC) and fixed bonobo transport duration (transit time $=24.00 \mathrm{~h}$ ).

very long distance; right skewness $=0.81$; Kurtosis $=3.38$; see (Nathan $\&$ Muller-Landau, 2000) for the different shapes of dispersal kernels). Bonobos disperse seeds over long distances, with $97.9 \%$ of the dispersal distances longer than $100 \mathrm{~m}$. There is no annual effect on bonobo dispersal distance (from 2007 to 2011, four years tested: $H=7.6939, \mathrm{df}=4, p=0.1035$ ) but the seasons seems to affect the group travel distance (September-January $=$ $1422 \mathrm{~m}$ on average, March-April $=1284 \mathrm{~m}$, February $($ dry $)=1132$, MayAugust (dry) $=1337 \mathrm{~m}$ tested: $H=17.4279, \mathrm{df}=3, p=0.000577)$. The main plant species tested (Cissus dinklagei $(N=173)$, Dialium sp. (362), Gambeya lacourtiana (56), Grewia sp. (97), Pancovia laurentii (73), Placodiscus paniculatus (48), Polyalthia suaveolens (61), Treculia africana (21)), from large G. lacourtiana to medium tree species (P. paniculatus and 


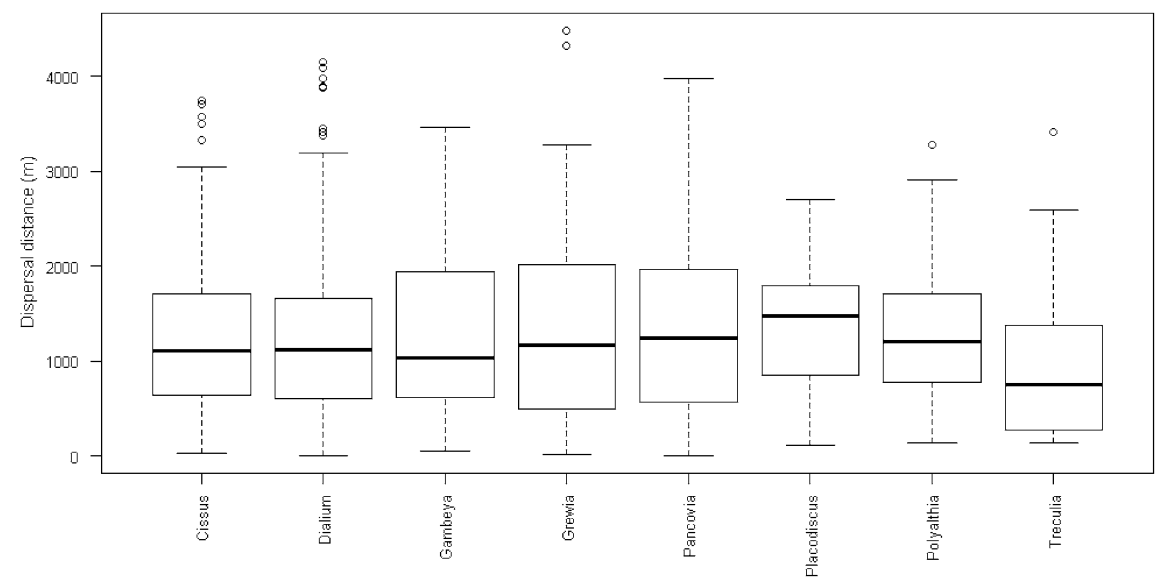

Figure 5. Seed dispersal distances induced by bonobo group for eight plant species (Cissus dinklagei $(N=173)$, Dialium sp. (362), Gambeya lacourtiana (56), Grewia sp. (97), Pancovia laurentii (73), Placodiscus paniculatus (48), Polyalthia suaveolens (61), Treculia africana (21)) at LuiKotale, DRC.

P. suaveolens) (see Table 1 for average dbh) did not significantly affect the dispersal distance induced by the bonobo ranging behaviour $(H=8.3769$, $\mathrm{df}=7, p=0.3005$ ) (Figure 5). The hypothesis on interspecific differences in seed dispersal distance was not supported.

\section{Discussion}

Our findings provide an analysis based on long-term data, of differences in dispersal distance among fleshy-fruited plants disseminated by the same endozoochoric dispersal vector. Surprisingly, all the fleshy-fruited species are dispersed at the same average distance, whatever the feeding time on the fruiting plant, their fruit quality and abundance: $1.3 \mathrm{~km}$ on average. This is a remarkable long dispersal distance with $97.9 \%$ of the seed transports superior to $100 \mathrm{~m}$ away from the parent plants. However, other extensive studies are required for seed dispersal comparison with other frugivores and other bonobo communities. Tsuji and his colleagues found a lowest dispersal distance induced by a Wamba community with an average distance of 783 and $777 \mathrm{~m}$ while foraging on two Dialium species (Tsuji et al., 2010b). This difference can be due to low sample size, a seasonal effect or a different community behaviour and ressource availability at Wamba). Bonobos seems to move at homogenous and regular distances from food patches. This could 
be due to the regular ranging behaviour and consistent travel times of bonobo groups, whatever the quality and quantity of the fruit they currently feed on. This interpretation does not fit with predictions of optimal foraging theory which suggest that animals would adapt their foraging investment (such as travel) according to food and nutrients availability. One potential explanation is the stochastic phenology of fruiting species at the site (Fruth et al., unpubl. data). This unpredictability could force bonobos to forage permanently for food and then regularly disperse the seeds at long distances. Another unverified hypothesis is differential ripening for these species. With asynchrony in ripe fruit availability, frugivores cannot forage for long sessions in the same area. However, further studies are needed on differential ripening in tropical plants. Surprisingly in another study, we found that seed size does not seem to affect transit time (Beaune et al., 2013a), unlike other animals, where a shorter gut passage is induced by smaller seed size (Westcott et al., 2005). Whatever their differences in seed/fruit size, colour, fruit quality and quantity, the fruiting-species traits did not seem to affect sufficiently the bonobo transit time and foraging behaviour for an effect on their seed dispersal distance.

Extensive seed dispersal among communities homogenises species composition, and eventually makes competitive ability dependent on global rather than local abundances, thus facilitating domination by the single most abundant species (Levin et al., 2003). This is the case here with bonobos as dispersal vectors. Seed dispersal limitation in distance (Muller-Landau et al., 2008) does not exist for different plant species sharing the same dispersers.

The assumption in the theoretical dispersal model that animals move randomly in space (Levin et al., 2003) is supported by our finding for the distance parameter, which is consistent and without any plant species effect. This is coherent with mechanistic models of zoochoric seed dispersal (Cousens et al., 2010).

However we did not explore post-dispersal fate for seed, which surely shapes species distribution (Réjou-Méchain et al., 2011). Several studies have shown that the interaction between environmental heterogeneity and the biological characteristics of species can influence distribution patterns at various spatial scales (Muller-Landau, 2004; ter Steege et al., 2006). Negative density dependence with environmental filtering contributes to community assembly (Paine et al., 2012). Nevertheless, it has also been shown that dispersal syndrome predicts spatial distribution, which is relatively dispersed 
for zoochoric species (Seidler \& Plotkin, 2006). For species using large mammals such as the bonobo, we show that seed dispersal is long-distance but without interspecific differences; although interspecific difference in fruit characteristics is wide. Do species dispersed by the same partner share the same distribution pattern? Studies have hypothesised that spatial patterns are highly context dependent but can be predicted by dispersal syndrome (Réjou-Méchain et al., 2011) and plant traits (Muller-Landau et al., 2008). Our hypothesis goes further with spatial prediction, trait-based generalisation and modelling of seed dispersal in tropical forests, based not on fruit characteristics, but rather on the disperser variable itself (elephant, bonobo, guenon, bat, hornbill, etc.).

To conclude, fruit traits of a species (quantity and quality) did not seem to affect disperser behaviour in relation to dispersal distance. Our finding leads to new questions about possible plant adaptations to force zoochoric partners to move constantly within their range. This research challenges the validity of optimal foraging theory predictions, at least in the case of bonobo ecology, as nutrient and food availability did not affect foraging and travel investment. The seed dispersal limitation theory explains how plant biodiversity is maintained, however bonobos induce homogenous dissemination in their ecosystem and thus dominant species could overcompete other species.

\section{Acknowledgements}

We thank the Institut Congolais pour la Conservation de la Nature (ICCN) for granting permission to conduct research at Salonga National Park, and also the Lompole village for granting permission to access the forest of their ancestors. Research at LuiKotale was conducted under the auspices and with financial support of the Max Planck Society, the German Ministry of Education and Research, the Conseil Régional de Bourgogne, the SFE and SFDP (France). We thank the international and local staff of LuiKotale for their help, Carmela Chateau-Smith for proofreading the English and the reviewers for their valuable suggestions.

\section{References}

Beaune, D. (2012). Latest news from the bonobos: Pan paniscus myths and realities. - Rev. Primatol. 4, DOI:10.4000/primatologie.1090. 
Beaune, D., Bretagnolle, F., Bollache, L., Hohmann, G., Surbeck, M., Bourson, C. \& Fruth, B. (2013a). The bonobo-Dialium positive interactions: seed dispersal mutualism. - Am. J. Primatol. 75: 394-403.

Beaune, D., Bretagnolle, F., Bollache, L., Hohmann, G., Surbeck, M. \& Fruth, B. (2013b). Seed dispersal strategies and the threat of defaunation in a Congo forest. - Biodiv. Conserv. 22: 225-238.

Beaune, D., Bretagnolle, F., Bollache, L., Bourson, C., Hohmann, G. \& Fruth, B. (2013c). Ecological services performed by the bonobo (Pan paniscus): seed dispersal effectiveness in tropical forest. - J. Trop. Ecol. 29: 367-380.

Beaune, D., Fruth, B., Bollache, L., Hohmann, G. \& Bretagnolle, F. (2013d). Doom of the elephant-dependent trees in a Congo tropical forest. — Forest Ecol. Manage. 295: 109117.

Campos-Arceiz, A. \& Blake, S. (2011). Megagardeners of the forest - the role of elephants in seed dispersal. - Acta Oecol. 37: 542-553.

Carlo, T.A. \& Morales, J.M. (2008). Inequalities in fruit-removal and seed dispersal: consequences of bird behaviour, neighbourhood density and landscape aggregation. - J. Ecol. 96: 609-618.

Chapman, C.A., Chapman, L.J., Wrangham, R., Hunt, K., Gebo, D. \& Gardner, L. (1992). Estimators of fruit abundance of tropical trees. - Biotropica 24: 527-531.

Clark, C., Poulsen, J. \& Parker, V. (2001). The role of arboreal seed dispersal groups on the seed rain of a lowland tropical forest. - Biotropica 33: 606-620.

Clark, C., Poulsen, J., Bolker, B., Connor, E. \& Parker, V. (2005). Comparative seed shadows of bird-, monkey-, and wind-dispersed trees. - Ecology 86: 2684-2694.

Côrtes, M.C. \& Uriarte, M. (2012). Integrating frugivory and animal movement: a review of the evidence and implications for scaling seed dispersal. — Biol. Rev. 88: 226-254.

Cousens, R.D., Hill, J., French, K. \& Bishop, I.D. (2010). Towards better prediction of seed dispersal by animals. - Funct. Ecol. 24: 1163-1170.

Fleming, T.H. (1979). Do tropical frugivores compete for food? - Am. Zool. 19: 1157-1172.

Forget, P.-M., Jordano, P., Lambert, J.E., Böhning-Gaese, K., Traveset, A. \& Wright, S.J. (2011). Frugivores and seed dispersal (1985-2010); the 'seeds' dispersed, established and matured. - Acta Oecol. 37: 517-520.

Fruth, B. \& Hohmann, G. (1993). Ecological and behavioral aspects of nest building in wild bonobos (Pan paniscus). — Ethology 94: 113-126.

Gardener, C., McIvor, J. \& Jansen, A. (1993). Passage of legume and grass seeds through the digestive tract of cattle and their survival in faeces. - J. Appl. Ecol. 30: 63-74.

Hohmann, G. \& Fruth, B. (2003). Lui Kotal - a new site for field research on bonobos in the Salonga National Park. — Pan Afr. News 10: 25-27.

Hohmann, G., Fowler, A., Sommer, V. \& Ortmann, S. (2006). Frugivory and gregariousness of Salonga bonobos and Gashaka chimpanzees: the influence of abundance and nutritional quality of fruit. - In: Feeding ecology in apes and other primates (Hohmann, G., Robbins, M. \& Boesch, C., eds). Cambridge University Press, Cambridge, p. 123-159. 
Hohmann, G., Potts, K., N'Guessan, A., Fowler, A., Mundry, R., Ganzhorn, J.U. \& Ortmann, S. (2010). Plant foods consumed by Pan: exploring the variation of nutritional ecology across Africa. - Am. J. Phys. Anthropol. 141: 476-485.

Howe, H.F. \& Miriti, M.N. (2004). When seed dispersal matters. — BioScience 54: 651-660.

Idani, G. (1986). Seed dispersal by pygmy chimpanzees (Pan paniscus): a preliminary report. — Primates 27: 441-447.

Jordano, P. (1995). Angiosperm fleshy fruits and seed dispersers: a comparative analysis of adaptation and constraints in plant-animal interactions. - Am. Nat. 145: 163-191.

Jordano, P., García, C., Godoy, J.A. \& García-Castaño, J.L. (2007). Differential contribution of frugivores to complex seed dispersal patterns. - Proc. Natl. Acad. Sci. USA 104: 3278-3282.

Kano, T. \& Mulavwa, M. (1984). Feeding ecology of the pygmy chimpanzees (Pan paniscus) of Wamba. - In: The Pygmy chimpanzee: evolutionary biology and behavior (Susman, R.L., ed.). Plenum Press, New York, NY, p. 435.

Leighton, M. (1993). Modeling dietary selectivity by Bornean orangutans: evidence for integration of multiple criteria in fruit selection. - Int. J. Primatol. 14: 257-313.

Lenz, J., Fiedler, W., Caprano, T., Friedrichs, W., Gaese, B.H., Wikelski, M. \& BöhningGaese, K. (2010). Seed-dispersal distributions by trumpeter hornbills in fragmented landscapes. — Proc. Roy. Soc. Lond. B: Biol. Sci. 278: 2257-2264.

Levey, D.J. \& Grajal, A. (1991). Evolutionary implications of fruit-processing limitations in cedar waxwings. - Am. Nat. 138: 171-189.

Levin, S.A., Muller-Landau, H.C., Nathan, R. \& Chave, J. (2003). The ecology and evolution of seed dispersal: a theoretical perspective. - Annu. Rev. Ecol. Evol. Syst. 34: 575-604.

McConkey, K.R. \& Chivers, D.J. (2007). Influence of gibbon ranging patterns on seed dispersal distance and deposition site in a Bornean forest. - J. Trop. Ecol. 23: 269.

Muller-Landau, H.C. (2004). Interspecific and inter-site variation in wood specific gravity of tropical trees. - Biotropica 36: 20-32.

Muller-Landau, H.C., Wright, S.J., Calderón, O., Condit, R. \& Hubbell, S.P. (2008). Interspecific variation in primary seed dispersal in a tropical forest. — J. Ecol. 96: 653-667.

Nathan, R. \& Muller-Landau, H.C. (2000). Spatial patterns of seed dispersal, their determinants and consequences for recruitment. — Trends Ecol. Evol. 15: 278-285.

Paine, C.E.T., Norden, N., Chave, J., Forget, P.-M., Fortunel, C., Dexter, K.G. \& Baraloto, C. (2012). Phylogenetic density dependence and environmental filtering predict seedling mortality in a tropical forest. - Ecol. Lett. 15: 34-41.

Poulsen, J.R., Clark, C.J., Connor, E.F. \& Smith, T.B. (2002). Differential resource use by primates and hornbills: implications for seed dispersal. — Ecology 83: 228-240.

Réjou-Méchain, M., Flores, O., Bourland, N., Doucet, J.-L., Fétéké, R.F., Pasquier, A. \& Hardy, O.J. (2011). Spatial aggregation of tropical trees at multiple spatial scales. J. Ecol. 99: 1373-1381.

Russo, S.E., Portnoy, S. \& Augspurger, C.K. (2006). Incorporating animal behavior into seed dispersal models: implications for seed shadows. — Ecology 87: 3160-3174.

Schupp, E.W., Jordano, P. \& Gomez, J.M. (2010). Seed dispersal effectiveness revisited: a conceptual review. — New Phytol. 188: 333-353. 
Seidler, T.G. \& Plotkin, J.B. (2006). Seed dispersal and spatial pattern in tropical trees. PLoS Biol. 4: e344.

Spiegel, O. \& Nathan, R. (2007). Incorporating dispersal distance into the disperser effectiveness framework: frugivorous birds provide complementary dispersal to plants in a patchy environment. - Ecol. Lett. 10: 718-728.

ter Steege, H., Pitman, N.C.A., Phillips, O.L., Chave, J., Sabatier, D., Duque, A., Molino, J.-F., Prevost, M.-F., Spichiger, R., Castellanos, H., von Hildebrand, P. \& Vasquez, R. (2006). Continental-scale patterns of canopy tree composition and function across Amazonia. - Nature 443: 444-447.

Tsuji, Y., Morimoto, M. \& Matsubayashi, K. (2010a). Effects of the physical characteristics of seeds on gastrointestinal passage time in captive Japanese macaques. - J. Zool. 280: 171-176.

Tsuji, Y., Yangozene, K. \& Sakamaki, T. (2010b). Estimation of seed dispersal distance by the bonobo, Pan paniscus, in a tropical forest in Democratic Republic of Congo. - J. Trop. Ecol. 26: 115-118.

Westcott, D.A., Bentrupperbaumer, J., Bradford, M.G. \& McKeown, A. (2005). Incorporating patterns of disperser behaviour into models of seed dispersal and its effects on estimated dispersal curves. - Oecologia 146: 57-67.

White, F. (1988). Party composition and dynamics in Pan paniscus. — Int. J. Primatol. 9: 179-193.

Willson, M. (1993). Dispersal mode, seed shadows, and colonization patterns. — Plant Ecol. 107: 261-280. 